\title{
LETTERS
}

Send your letters to the editor, British Dental Journal, 64 Wimpole Street, London W1G 8YS or by email to bdj@bda.org

Priority will be given to letters less than 500 words long. Letters should be typed. Authors must sign the letter, which may be edited for reasons of space

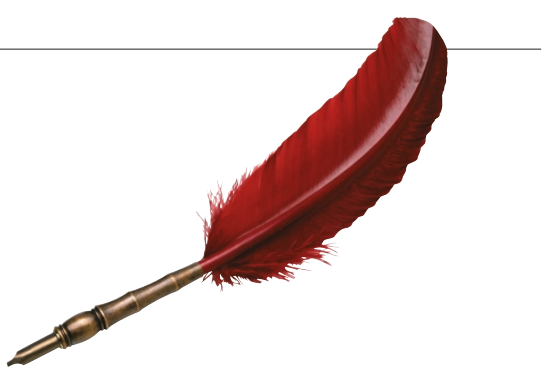

How can anyone be so sure that extractions are wise when views in the past have oscillated so widely and my recent research in Kenya has found so many primitive villagers with 32 teeth and space to spare?

They are correct in saying there is insufficient evidence to show that 'functional' appliances work but again, there is also insufficient evidence to show that they do not. Clinical evidence is inherently unreliable and it is probably wiser to rely on more basic evidence (Mew 2002). The unanswered question is 'Why is malocclusion currently endemic in civilized society when our direct ancestors of 20,000 years ago had few such problems'?

\section{J. Mew}

Sussex

1. Mew JRC. The aetiology of temporomandibular disorders: a philosophical overview. Eur J Orthod 1997: 19:249-258.

2. Mew JRC. Are random controlled trials appropriate for orthodontics? Evid Based Dent 2002; 3: 35-36.

Sir, I have been following with interest the series of articles on orthodontics. In Part 7: 'Fact and fantasy in orthodontics' (BDJ 2004,196:143) the authors state in the summary of evidence-based dentistry that 'Orthodontics has little gold standard evidence'. I wonder where that leaves the basis for these articles, upon which the BDA has committed significant resources to create a handbook for general dental practitioners.

Could it be that, put into perspective, this whole series is another missive of well held opinions and that the material put forward by the authors, in the absence of 'gold standard' evidential support, falls into the realms of fantasy? The closing paragraph refers to this domination of forceful opinion and I believe it would be most helpful to the dental profession as a whole if this was acknowledged by the orthodontic establishment.

\section{H. Jones}

Surrey

Sir, I have enjoyed so far the orthodontic series by Drs Roberts-Harry et al. However I was surprised to see in the risks article such distinguished authors trotting out the old dogma on endocarditis at-risk patients. The excellent paper by Lucas et al published in the EJO in 2002 clearly concluded that only the placement of separators induces a significant bacteraemia.

The over prescription of antibiotics has been well documented - let's educate our colleagues to use them less!

\section{R. Bateman}

Kent

The authors respond: We would like to thank Drs Jones, Mew and Bateman for their letters. We would disagree with $\mathrm{Dr}$ Jones' view on the validity of the series of articles. The series covers a range of important principles ranging from patient assessment to appliance choices. For example, it is an empirical and scientific fact that fixed appliances are better than removable at most tooth movements (part 5) and that patient assessment is essential when devising a treatment plan (parts 2, 3 and 4).

In part 7 we highlight and acknowledge that like most clinical sciences, orthodontic proof is in its infancy. Recent publications in the Journal of Orthodontics and the American Journal of Orthodontics and Dentofacial Orthopaedics from the academics in Manchester have shown quite clearly that orthodontics is doing much to increase the scientific basis of clinical practice.

Although we do not presume to be the orthodontic establishment we feel that our closing paragraph acknowledges the 'domination of forceful opinion' and how misleading this can be. The same is true for almost all branches of dentistry.

We are grateful for the interest Mr Mew has shown in this series and his comments. Unfortunately we are not the 'establishment' and our views are based on the available evidence and not personal opinion.

We are also grateful for the interest $\mathrm{Dr}$ Bateman has shown in this popular series.

At the time of writing the orthodontic articles the Lucas article had not appeared in press. We disagree that we were 


\section{LETTERS}

\section{Collapse of NHS dentistry}

Sir, I read a recent article on dentistry in the Sunday Telegraph on February 22nd. This occupied a whole page and is one of the rare occasions when dentistry is mentioned in the press. I am appalled at the lack of interest shown by the BDA on the lack of propagation of information in a situation where it is extremely difficult to obtain a dentist under the NHS.

Even private treatment is difficult to obtain. I have been concerned about the collapse of NHS dentistry for the past 10 years. It would appear that our association has made no effort to liaise with the Ministry of Health. It is true to say that dentistry is relegated to the state of 'third world countries' where there is a better service. I am also disgusted at the cessation of the Benevolent Fund diary. P. W. Gaffith Cornwall

Ian Wylie, BDA Chief Executive responds: The BDA shares the concerns over access to dentistry and indeed it is this very issue, and the causes which lie behind it,

'trotting out old dogma'. We presented a balanced view supported by guidelines.

Further the article by Lucas et al is at variance with data from two other studies. This is acknowledged by Lucas et al in their discussion and reasons for this are presented. In their conclusions they suggest that a larger study is needed to clarify which procedures require antibiotic prophylaxis in children and adolescents with predisposing cardiac lesions. We accept the paper by Lucas et al is a quality manuscript. However we do not understand how anyone could take a dogmatic stance on this difficult topic when the authors of the Lucas paper are themselves unsure.

doi: 10.1038/sj.bdj.4811308

\section{Using the internet}

Sir, I read with interest the Opinion article entitled 'Keeping up with your patients' (BDJ 2004, 196:309) and happily admit to being one of the $38 \%$ of practitioners who send my CPD answers by post or fax. Whilst I do have the facility to submit my answers by email, it was a deliberate decision to use snail mail, as I strongly object to having my email address used for bulk mail shots and special offer advertisements.

Although this has not yet happened from a $B D J$ source, I would rather try to ensure that it does not happen at all. It was therefore with great disappointment that I read of the decision to charge the sum of which has prompted intensive lobbying. We have now completed one of the most thorough consultations of the profession in the BDA's history. The results (which are available on the BDA's website) will provide the BDA with a powerful tool to continue discussions with the Government over its proposals for primary care dental services. At times of great uncertainty, for profession and patients alike, the effective communication of reliable and accurate information is paramount. The BDA has gone to considerable lengths to keep its membership informed of developments and, in my view, also proved highly effective in forcing dentistry up both the political and media agenda. However, your correspondent is right to keep us on our toes and we will continue to use all available methods of communication, ranging from letters to individual members to postings on our website, to ensure our membership has as full a picture as possible of what is occurring during this time of change. doi: 10.1038/sj.bdj.4811309

$£ 10$ for administrative costs for fax and postal submissions for the Eastman/BDJ CPD programme. If only a small percentage of the $38 \%$ of the 5000 registered users were to continue to pay $£ 10$ each time, then somebody will still be making an awful lot of money. The sadness is that I suspect that it will be the retired practitioners without access to computers, who, whilst attempting to keep up with their CPD (having paid the full GDC retention fee) will suffer yet again.

\section{E. M. Robb}

Bristol

Sir, I read with interest your Opinion in $B D J 2004$ 196:309. At the beginning of the article, you state that ' $38 \%$ of dentists prefer to send their CPD answers by letter or fax rather than using the Internet'.

At the end of the article, you state that 'the percentage of dentists quoted at the start who are not electronically aware'.

Does that mean then that those 38\% are not electronically aware in general or just not aware of the internet system of recording $\mathrm{CPD}$ with the $B D J$ ?

Was that statement justified? (There was also a 'news item' a few pages later stating that there was a charge from next month for letters and faxes. Linked somehow?)

I pride myself on being very 'electronically aware'. I build computers, set up websites and intranets for my fellow colleagues, run a COMPLETELY paper free practice and am very interested in using technology to improve my working life and the lives of my patients, purely as a hobby. However, my last few CPD submissions were via fax and not the website. The reason I did this was purely for reasons of time, not because I do not know how to do it online.

When I read the articles and answer the CPD questions, I do not tend to be in front of my computer. I, like most people I presume, read the articles and mark the answers on the CPD page. Then it was just a simple matter of handing it to my secretary who quickly filled in the remaining details and faxed it off - easy! It was so easy, I did the work in my lunch hour in the pub downstairs and it did not interfere with my day. It actually takes longer to read and do the questions, then dial up to the internet, (which I have to do myself because I do not want my secretary to know my login), redo the questions and submit.

In these days, where time management and delegation are key ways to improve the efficiency and profitability of our businesses, we as principals need to spend as much time as possible in our working day doing the actual dentistry, while allowing other people to do jobs which distract from this. We would also like to go home at the end of the day without more paperwork to do (not that I am complaining about CPD!). Technology can often make our lives easier and quicker but it is not an ipso facto guarantee that computerising something will. I am technologically aware and feel that I am 'keeping up with my patients'!

\section{R. Endicott}

Eastbourne

Mike Grace, BDJ Editor responds: I would like to thank Dr Endicott for his thoughtful and well-argued response to my leader on 'Keeping up with your patients'. He is quite right, I should not have assumed that the $38 \%$ of responses to the BDJ/Eastman CPD by fax and letter meant that those dentists were not electronically and digitally aware, and I apologise for using the word 'are' instead of 'may be'. I also appreciate his arguments for sending in his responses to the CPD qestions using his secretary rather than key in the answers into his computer.

The problem with this is that the time and effort for keying the answers has switched to the staff at the Eastman (who administer the programme) and the volume of responses has overwhelmed them. This is the reason we are now having to charge for this rather than providing the service free to $B D A$ members, as was originally hoped. With close to 2,000 people now sending in CPD papers each issue the administrative 
burden of keying in 38\% of them is immense (especially for the one part-time administrator). We are hoping that charging a nominal sum for this administrative cost will result in many more dentists (or their secretaries) submitting their responses via email.

Out of interest the leader was written several weeks before the decision was taken to charge this administrative fee, and its appearance at the same time as the announcement was published was purely coincidental (but useful).

doi: 10.1038/sj.bdj.4811313

\section{Options for change}

Sir, the following is a possible scenario between the two comedy sketch actors Bird and Fortune. Bird is a dentist, Fortune is a Minister in the Department of Health. Dentist: So, what exactly are you trying to achieve with the new contract?

Minister: Simple, we want to secure access and comprehensive dental treatment for all citizens under the NHS.

Dentist: But we have a shortage of dental manpower. We are already working as fast as we can. Some people feel that quality has suffered as well. In the light of this how can we possibly achieve your aims? Minister: Well, we want you to see your patients less often and to do different dentistry on them.

Dentist: When you say different do you mean less dentistry?

Minister: That's right - less and different dentistry.

Dentist: Does that mean you think we are over-prescribing right now?

Minister: Oh no, no no! I wouldn’t say that! You chaps are doing a jolly fine job. I wouldn't want to put my fingers in other people's mouths.... jolly fine job indeed. Dentist: So let me get this right. You say we are not doing the wrong kind of dentistry right now, but you want us to provide different dentistry so that we can see more patients from April 2005.

Minister: That's right. And you will be able to spend more time with them so that you can persuade them to give up smoking and ask them about their holidays.

Dentist: But minister, if you agree that the dentistry we are doing now is appropriate to our patients' needs and the manpower crisis still exists, then how can we see more patients and spend more time with each one?

Minister: That's simple. We have empowered the PCTs to sort it out. Rather clever isn't it? I say, was that Alice I saw talking to a man with a top hat?

\section{Shupac}

By email

doi: 10.1038/sj.bdj.4811310

\section{Not paying attention?}

Sir, I have just read through the Government publication Framework Proposals for Primary Dental Services in England from 2005 and I am very much put in mind of a recent television programme that I watched in the aftermath of the war in Iraq.

There, one of the people being interviewed - an American - said that one of the faults of the American administration was that it had not paid nearly enough attention to the views of doubters and sceptics and the people who were of the opinion that this was not the way that things would turn out, once the war was over.

It had been rushed through with a feeling of triumph by a small group of people who had the general attitude 'we know best'.

I cannot help feeling that there are huge similarities with the framework proposals. I can see the Government staring another 'British Leyland' in the face.

What it is intending doing is taking a largely 'private enterprise' culture NHS dentistry organisation, chucking money at it and just hoping that everything will turn out alright in the end. I have my doubts.

J. Hartley

Peterborough

doi: 10.1038/sj.bdj.4811311

\section{X-rays}

Sir, You published a letter in BDJ 2004, 196:65 accompanied with X-rays which your correspondent had sent to you illustrating the revelant topic.

Unfortunately, these appeared as positive images difficult to interpret. Practising dentists are used to viewing radiographs in the negative form.

I am sure that this was an error which should be avoided in the future having regard to the worldwide circulation which the $B D J$ enjoys.

\section{K. Millman}

Devon

doi: $10.1038 /$ sj.bdj.4811312

The images below were printed incorrectly in BDJ 196:65. They are printed correctly here.

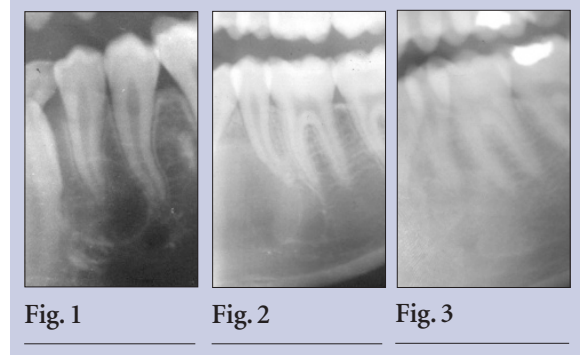

